\title{
EVALUATION OF ANTIMICROBIAL EFFECT OF TWO PROPOLIS FORMULAE ON STREPTOCOCCUS MUTANS AND CANDIDA ALBICANS: A RANDOMIZED CLINICAL TRIAL
}

\author{
Hend S. El-Allaky ${ }^{1 *} B D S$, Nadia A. Wahba ${ }^{2} P h D$, Dalia M. Talaat ${ }^{3} P h D$. Azza S. Zakaria ${ }^{4} P h D$ \\ ABSTRACT
}

INTRODUCTION: Streptococcus mutans is considered to be the most cariogenic microorganism. However, candida albicans has also been isolated from dental plaque of high caries risk children. Therefore, uses of natural antimicrobial agents such as propolis have been established as an adjunctive approach for oral health care.

OBJECTIVES: the aim of this study was to evaluate the antibacterial and antifungal effects of propolis chewing gum compared to propolis mouthwash.

MATERIALS AND METHODS: Sixty high caries risk children aged 6 to 8 were randomly assigned into two groups. Group I received propolis chewing gum and Group II received propolis mouthwash. A baseline and final plaque samples were obtained from each participant before and after intervention respectively within 14 days interval. All participants were asked to refrain from eating or brushing on the sampling days. Samples were sent immediately to the laboratory for microbial assessment.

RESULTS: data revealed that both study groups showed significant differences $(\mathrm{P} \leq 0.001)$ in streptococcus mutans and candida albicans counts before and after intervention. But there was no significant difference among the comparative groups.

CONCLUSION: It was demonstrated that propolis chewing gum and propolis mouthwash can be used as antimicrobial agents.

KEYWORDS: Propolis, Chewing gum, Mouthwash, Antimicrobial

RUNNING TITLE: Comparison of antimicrobial effect of two propolis vehicles.

1 Demonstrator of Pediatric Dentistry, Pediatric Dentistry Department, Faculty of Dentistry, Benghazi University, Libya.

2 Professor of Pediatric Dentistry, Pediatric Dentistry and Dental Public Health Department, Faculty of Dentistry, Alexandria University, Egypt.

3 Associate Professor of Pediatric Dentistry, Pediatric Dentistry and Dental Public Health Department, Faculty of Dentistry, Alexandria University, Egypt.

4 Associate Professor of Microbiology and Immunology, Microbiology and Immunology Department, Faculty of Pharmacy, Alexandria University, Egypt

*Corresponding author:

Email: hend.elallaky@alexu.edu.eg

\section{INTRODUCTION}

Dental plaque is the main etiological factor causing dental caries, gingival and periodontal disease. These conditions appear as a result of interaction between the pathogenic dental plaque biofilm and the host tissue response (1).

The most important causative agent of dental caries is well known to be streptococcus mutans (S. mutans) (2). However, recently candida albicans (C. albicans) has been linked with its synergistic relationship with streptococcus mutans in caries process (3). These oral microorganisms are frequently detected in dental plaque (4). Therefore, improvement of oral hygiene is essential to eliminate the supragingival plaque and the accumulated bacteria (1). Consequently, this prevents and arrests the development of caries in high caries risk children (5). Regular personnel oral hygiene is required for proper removal of supragingival plaque (6). Coelho Leal et al 2002 (7) found that tooth brushing is the most effective method

of actively removing plaque at home. Nevertheless, it is generally known that effective brushing may be inefficient especially in young age children (8). Van der Weijden et al 2015 (9) reported in their study that the adjunct use of antimicrobial agents offers advantages in terms of prevention of caries and gingival inflammation. Chlorhexidine mouth wash is the most persistent antimicrobial agent for reducing plaque buildup (10). However, when used for long time, it can lead to teeth staining (11), hypersensitivity reactions and burning sensation of the oral soft tissue (12) .These adverse reports increase the demands to explore alternative agents for oral health promotion especially in young children. As a result, this led to paying more attention to natural and herbal products (13).

Propolis is one of the most promising natural products to prevent oral disease. It has antibacterial, antiviral, antifungal 
(14), antioxidant (15) and anti-inflammatory effects (16) with little or no side effects $(13,17)$. De Camargo et al 2015 (18) in their study showed that propolis inhibit the growth of $\mathrm{S}$. mutans, streptococcus pyogenes and staphylococcus aureus. Moreover, Siqueira et al 2015 (19) explored the fungicidal activities of propolis on candida species isolated from saliva of chronic periodontitis cases. The antimicrobial properties of propolis can thus be an alternative measure to prevent dental caries when used as an active agent in mouth washes (20). However; in some cases where it is difficult to use mouthwash, other vehicles are required for oral care. Chewing gum with antiplaque agent has been tested as an additional tool for daily oral care. Results showed that it can be an appropriate vehicle for the release of antiplaque agent $(21,22)$. On the other hand, Ercan et al 2015 (23) investigated the effect of propolis chewing gum compared to propolis containing mouthwash on gingival inflammation and plaque accumulation of children. Results revealed that propolis mouthwash was highly effective than using chewing gum.

Considering the importance of oral health with the potential increase in plaque accumulation and microbial colonization among children who are high caries risk, clinicians should establish the worth of self-performing antimicrobial plaque control measures as an adjunct to the mechanical measures.

Since little information is available on the best vehicle of administration that would promote children's use of propolis, this study was designed to evaluate the effect of two different methods of propolis administration on S. mutans and candida albicans counts. The null hypothesis tested was that there is no difference in antibacterial and antifungal effect of propolis delivered through mouth wash or chewing gum.

\section{MATERIALS AND METHODS}

\section{Study design}

This study was double blinded randomized clinical trial, two-group parallel arms. It was setup and reported according to the CONSORT Statement. The PICO question was " Do high caries risk children (P) using propolis chewing gum (I) in comparison (C) to propolis mouthwash show same streptococcus mutans or candida albicans counts after 14 days (O). Ethical approval was obtained by Dental Research Ethics Committee Faculty of Dentistry, Alexandria University (\#IRB NO 00010556- IORG 0008839). Prior to commencement of study, parent/ caregivers of all children were asked to provide an informed written consent for examination and publication, after explanation of the study's aims and procedure.

\section{Study setting}

Children were selected from outpatient clinic of the Pediatric Dentistry and Dental Public Health Department, Faculty of Dentistry, Alexandria University, Egypt. The material was prepared in, Faculty of Pharmacy, Alexandria University, Egypt. Microbiological assessment was performed at the Department of Microbiology and Immunology, Faculty of Pharmacy, Alexandria University, Egypt.

\section{Sample size estimation}

The minimal sample size was calculated based on a previous study conducted by Rubido et al 2014 (24). A sample size of 25 children per group (total sample size $=50$ ) was the required sample to detect 0.5280 change in the primary outcome. A power of $80 \%$ was used to detect a significantly meaning difference of bacterial and fungal count reduction in dental plaque in high caries risk children receiving chewing gum containing propolis compared to those receiving mouthwash containing propolis. The estimated sample size per group was increased to 30 children per group to control attrition bias (25). The selected children aged 6 to 8years. They were free from any medical illness except they were diagnosed as high caries risk patients as defined by the guidelines of the American Academy of Pediatric Dentistry (AAPD) (26). In addition they were classified as cooperative according to Frankl rating (score 3 \& 4) (27). Others who had any oral infection or received any antibiotic treatment for two weeks before or during the study and those who received any propolis product previously were excluded from the study.

\section{Randomization and allocation concealment}

The selected participants were randomly assigned using a computer-generating list of random numbers to one of the two arms. They were randomly divided into two groups according to the type of treatment. Allocation was performed by a trial independent individual and the allocation ratio was intended to be equal. Each group received a code, and the main supervisor randomly allocated the codes to the groups (I and II). Coding was done by computer software (Generate Random Codes Tools). Independent trial personnel unfolded the blinded codes at the end of statistical analysis.

\section{Grouping}

Group I $(\mathrm{N}=30)$ : children received propolis chewing gum and Group II (N=30): children who used propolis mouth rinse.

\section{Blinding}

The investigator and the participants were not blinded to the treatment type as each group has to be given different instructions according to their treatment protocol. However, the statistician and the microbiologist were blinded to the treatment group.

\section{Material preparation}

a) Propolis Chewing gum preparation:

$2 \%$ pure propolis, $20-35 \%$ gum base, $2.5 \%$ flavors, $0.3 \%$ sorbitol and $0.3 \%$ coloring substance. (28)

\section{b) Propolis mouthwash preparation:}

The formulation includes $2 \%$ pure raw propolis, $40 \mathrm{ml}$ flavors, $150 \mathrm{ml}$ propylene glycol, $60 \mathrm{~g}$ sorbitol, $0.1 \mathrm{~g}$ coloring substance and water. (29)

\section{Intervention}

All participants received oral prophylaxis and oral hygiene instructions before baseline assessment. They were advised to brush their teeth twice daily using a soft brush and pea-sized fluoridated toothpaste (30). Each child was instructed to refrain from tooth brushing, eating, or drinking (except water) in the morning day of sampling at least two hours before sampling procedure (31).

Participants who received chewing gum were instructed to chew a piece of gum for at least twenty minutes once after breakfast and another before bed time for two weeks while those who used mouthwash were instructed to rinse with $10 \mathrm{ml}$ present in the delivered preloaded tube for 60 seconds twice daily once after breakfast and another before bedtime for two 
weeks (32). Every child was given a follow up table to be signed by his/her parent/care giver after each use of propolis chewing gum in Group I or propolis mouthwash in Group II. The table included the child data regarding the name, age, group and the serial number given to the child.

\section{Sampling of dental plaque}

Two plaque samples were collected from each participant, a baseline plaque sample was collected after 48 hour from prophylaxis and another one was collected after fourteen days of the treatment period. Both samples were gathered by running a sterile toothpick over the whole teeth surfaces. This was immediately kept in $1 \mathrm{ml}$ sterile saline $(33,34)$ and sent for the microbiological assessment.

\section{Microbiological assessment of the plaque (29)}

1. Sample dilution

All samples were dispersed by vertexing for 30 seconds then 10 -fold serially diluted using sterile saline.

2. Culture

Aliquots of $20 \mathrm{ml}$ of each dilution were inoculated into freshly prepared blood agar, Mitis Salivarius agar (MSA) and Sabouraud agar media, using micro pipette. All media were incubated at $37^{\circ} \mathrm{C}$ for $48-72$ hours.

3. Isolation and Enumeration

Following the predetermined incubation period, colonies grown on the specified media were counted and represented as (CFU/ ml). S. mutans were identified on the basis of its characteristic morphology on Mitis Salivarius agar plates. Moreover, candida albicans were identified biochemically and microscopically on the basis of their morphology.

4. Colony count

The number of colonies were determined and expressed as colony forming units (CFU) using the following equation:

$\mathrm{CFU} / \mathrm{ml}=\mathrm{n}^{\circ}$ of colonies $\times$ dilution factor

Volume taken in ml (0.02)

\section{STATISTICAL ANALYSIS}

The data were analyzed by the use of SPSS software (SPSS version 25.0). Data were reviewed to check for any errors during data entry. Descriptive statistics were performed using frequencies and percentages for qualitative data, while mean and standard deviation (SD) were used for quantitative data. Normality was checked using descriptive statistics, plots (histogram and box plot) and Kolmogorov-Smirnov test. The level of statistical significance was set at 0.05 .

Per protocol analyses were followed (35). Differences between both groups were analyzed using Student's t test or Mann Whitney U test for normally and not normally distributed data, respectively. Percentage change of log values was calculated according to the formula [(final assessment-baseline assessment)/baseline assessment] x 100. Wilcoxon Sign Rank test were used to compare baseline and final assessment for intragroup comparisons

\section{RESULTS}

Three participants dropped out at the final follow up out of the 60 children but they were not replaced as there were 10 cases added to total estimated sample size to control the attrition bias. The mean age values of the participants were $(6.87 \pm 0.81)$. There was no significant difference regarding gender distribution among the two study groups $(\mathrm{P} \leq 0.84)$. There was a high significant difference between the mean values of the absolute total bacterial count before and after intervention in the two study groups $(\mathrm{P} \leq$
0.001). But by comparing the two groups at baseline and after intervention no significant differences in the total microbial count was recorded $(\mathrm{P} \leq 0.11, \mathrm{P} \leq 54)$ respectively. (Table 1 )

Each group showed statistically significant differences in absolute count of $S$. mutans after the intervention as compared to the baseline $(\mathrm{P} \leq 0.001)$. However, among the comparison groups there were no significant differences in the S. mutans count before and after treatment $(\mathrm{P} \leq 0.61, \mathrm{P} \leq 0.45)$ respectively (Table 2$)$.

Regarding counts of C. albicans, a complete elimination of candida albicans colonies were detected on Sabouraud agar plates after propolis using in both groups (Table 3)

Table 1: Shows Mean Absolute bacterial count and log values in study groups before and after intervention.

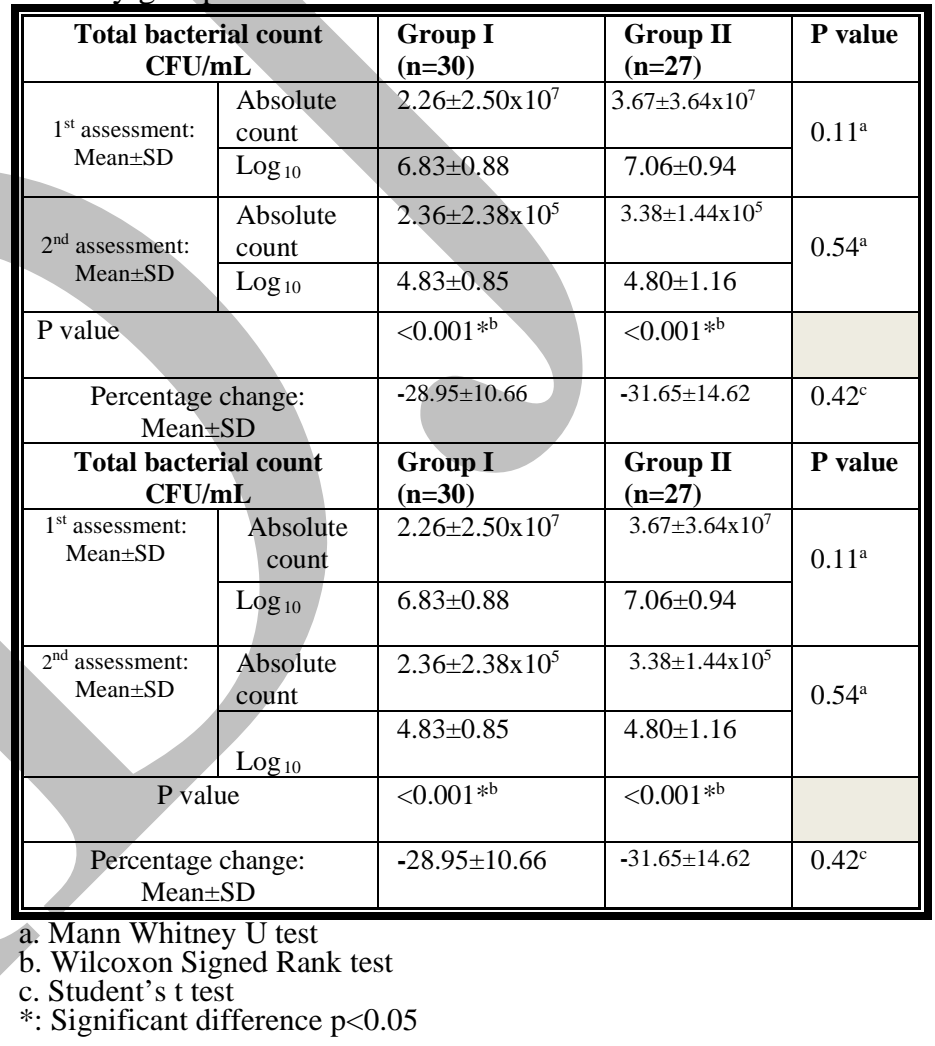

Table 2: Shows Mean absolute count and log values of $\mathrm{S}$. mutans count in plaque samples before and after intervention

\begin{tabular}{|c|c|c|c|c|}
\hline \multicolumn{2}{|l|}{ MS count } & $\begin{array}{l}\text { Group I } \\
(n=30)\end{array}$ & $\begin{array}{l}\text { Group II } \\
(\mathrm{n}=27)\end{array}$ & P value \\
\hline \multirow{2}{*}{$\begin{array}{l}1^{\text {st }} \text { assessment: } \\
\text { Mean } \pm \text { SD }\end{array}$} & Absolute & $4.04 \pm 7.95 \times 10^{6}$ & $2.54 \pm 3.00 \times 10^{6}$ & \multirow{2}{*}{$0.61^{\mathrm{a}}$} \\
\hline & $\log _{10}$ & $5.39 \pm 2.01$ & $5.87 \pm 0.95$ & \\
\hline \multirow{2}{*}{$\begin{array}{l}2^{\text {nd }} \text { assessment: } \\
\text { Mean } \pm \text { SD }\end{array}$} & $\begin{array}{c}\text { Absolute } \\
\text { count }\end{array}$ & $0.57 \pm 1.19 \times 10^{4}$ & $0.30 \pm 1.25 \times 10^{6}$ & \multirow[t]{2}{*}{$0.45^{\mathrm{a}}$} \\
\hline & $\log _{10}$ & $1.53 \pm 1.94$ & $2.05 \pm 2.36$ & \\
\hline \multicolumn{2}{|c|}{$\mathrm{P}$ value } & $<0.001 * b$ & $<0.001^{* b}$ & \\
\hline \multicolumn{2}{|c|}{$\begin{array}{c}\text { Percentage change: } \\
\text { Mean } \pm \text { SD }\end{array}$} & $-64.85 \pm 38.30$ & $-66.47 \pm 37.84$ & $0.89^{\mathrm{a}}$ \\
\hline
\end{tabular}

a. Mann Whitney U test

b. Wilcoxon Signed Rank test 
Table 3: Shows mean absolute C. albicans count and log values in study groups before and after intervention

\begin{tabular}{|c|c|c|c|c|}
\hline \multicolumn{2}{|c|}{ Candida count } & \multirow{2}{*}{\begin{tabular}{|l|}
$\begin{array}{l}\text { Group I } \\
(\mathbf{n}=\mathbf{3 0})\end{array}$ \\
$0.55 \pm 2.32 \times 10^{4}$
\end{tabular}} & \multirow{2}{*}{\begin{tabular}{|l|}
$\begin{array}{c}\text { Group II } \\
(\mathbf{n}=\mathbf{2 7})\end{array}$ \\
$2.21 \pm 9.60 \times 10^{4}$
\end{tabular}} & $P$ value \\
\hline $\begin{array}{l}1^{\text {st }} \text { assessment: } \\
\text { Mean } \pm \text { SD }\end{array}$ & $\begin{array}{l}\text { Absolute } \\
\text { count }\end{array}$ & & & \multirow[t]{2}{*}{$0.01 *$ 标 } \\
\hline & $\log _{10}$ & $0.86 \pm 1.62$ & $2.10 \pm 1.87$ & \\
\hline \multirow[t]{2}{*}{$\begin{array}{l}2^{\text {nd }} \text { assessment: } \\
\text { Mean } \pm \text { SD }\end{array}$} & $\begin{array}{l}\text { Absolute } \\
\text { count }\end{array}$ & 0 & 0 & \multirow[t]{2}{*}{ - } \\
\hline & $\log _{10}$ & 0 & 0 & \\
\hline \multicolumn{2}{|l|}{$\mathrm{P}$ value } & - & - & \\
\hline \multicolumn{2}{|c|}{$\begin{array}{c}\text { Percentage change: } \\
\text { Mean } \pm \text { SD }\end{array}$} & -100 & -100 & - \\
\hline
\end{tabular}

\section{DISCUSSION}

The main aim of this study was to evaluate the antibacterial and antifungal effect of propolis using two vehicles, chewing gum and mouthwash, on high caries risk children. The results showed a significant percent reduction in absolute colony count of S. mutans within group comparison. This result was supported by previous studies enhanced the antibacterial effect of propolis extracts (36-38). Conversely, Duailibe et al (39) found that half of the collected samples showed an increase or no changes in S. mutans after using mouthwash containing propolis. This variation between studies could be due to difference in study design, study period or age of the participants.

In this study no candidal colonies were seen on Sabouraud agar plates after using propolis either as chewing gum or mouthwash, this highlight the antifungal effect of propolis in both vehicles despite the low absolute mean count of $C$. albicans in both groups at baseline as not all cultured plaque sample revealed presence of candida initially but once they were detected at baseline they were eliminated at the final cultured sample after intervention. This goes in line with Herrera et al (40), who tested the antifungal properties of six commercial products containing propolis against candidal species. Their results showed that all propolis extract inhibited the growth of candida. However, there was a significant difference between different products which conflict with this study as there was no significant difference of the antifungal effect between both propolis vehicles. This may be explained as the innative properties of propolis may differ according to different origin while in this study the same type of propolis was incorporated in both vehicles. Therefore, there was no significant difference among group comparison, chewing gum and mouthwash containing propolis, neither in streptococcus nor in candidal count. Results may be affected by the short trial period. Also participant compliance is considered a factor of limitation that could introduce bias and affect the trial results. Within the limitation of this study, propolis established to have a significant effect as antibacterial and antifungal agent either when used as chewing gum or mouthwash. The results suggest accepting the null hypothesis and support the use of propolis as antimicrobial agent in different vehicles.

\section{CONCLUSION}

Propolis proved to reduce S. mutans and C. albicans count either when incorporated in chewing gum or mouthwash vehicle. Therefore, it is suggested to be used as antimicrobial agent in high caries risk children.

\section{CONFLICT OF INTEREST}

The authors declare no conflict of interest. This research did not receive any specific grant from funding agencies in the public, commercial, or not-for-profit sectors.

\section{REFERENCES}

1. Seneviratne CJ, Zhang CF, Samaranayake LP. Dental Plaque Biofilm in oral Health and Disease. Chinese J Dent Res. 2011;14:87-94.

2. Thenisch NL, Bachmann LM, Imfeld T, Leisebach Minder T, Steurer J. Are Mutans Streptococci Detected in Preschool Children a Reliable Predictive Factor for Dental Caries Risk? A Systematic Review. Caries Res. 2006;40:366-74.

3. Nikawa H, Yamashiro H, Makihira S, Nishimura M, Egusa $\mathrm{H}$, Furukawa $\mathrm{M}$, et al. In vitro cariogenic potential of Candida albicans. Mycoses. 2003;46:471-8.

4. De Carvalho FG, Silva DS, Hebling J, Spolidorio LC, Spolidorio DMP. Presence of mutans streptococci and Candida spp. in dental plaque/dentine of carious teeth and early childhood caries. Arch Oral Biol. 2006;51:1024-8.

5. Gurenlian JR. The Role of dental paque biofilm in oral health. J Dent Hyg. 2007;81:1-11.

6. Weijden V Der, Kpk H. A systematic review of the effectiveness of self-performed mechanical plaque removal in adults with gingivitis using a manual toothbrush. J Clin Periodontol. 2005;32:214-28.

7. Coelho Leal S, Barreto Bezerra AC, Ayrton de Toledo O. Effectiveness of teaching methods for toothbrushing in preschool children. Braz Dent J. 2002;13:133-6.

8. Gunsolley JC. A meta-analysis of six-month studies of antiplaque and antigingivitis agents. JADA. 2006;137:1649-57.

9. Van der Weijden FA, Van der Sluijs E, Ciancio SG, Slot DE. Can Chemical Mouthwash Agents Achieve Plaque/Gingivitis Control? Dent Clin North Am. 2015;59:799-829.

10. James P, Worthington H V, Parnell C, Harding M, Lamont $\mathrm{T}$, Cheung $\mathrm{A}$, et al. Chlorhexidine mouthrinse as an adjunctive treatment for gingival health. Cochrane Database Syst Rev. 2017 Mar 31;3.

11. Zanatta FB, Antoniazzi RP, Rösing CK. Staining and calculus formation after $0.12 \%$ chlorhexidine rinses in plaque-free and plaque covered surfaces: a randomized trial. J Appl Oral Sci. 2010;4:515-21.

12. Pemberton MN, Gibson J. Chlorhexidine and hypersensitivity reactions in dentistry. $\mathrm{Br}$ Dent $\mathrm{J}$. 2012;213:547-50.

13. Malhotra S, Gupta V. Use of propolis in pediatric dentistry. J Dent Allied Sci. 2014;3:93-8.

14. Kujumgieva A, Tsvetkovaa I, Serkedjievaa Y, Bankovab V, Christovb R, Popovb S. Antibacterial, antifungal and antiviral activity of propolis of different geographic origin. 
J Ethnopharmacol. 1999;64:235-40.

15. Betances-Salcedo E, Revilla I, Vivar-Quintana A, González-Martín M. Flavonoid and Antioxidant Capacity of Propolis Prediction Using Near Infrared Spectroscopy. Sensors. 2017;17:1647-59.

16. Mossalayi MD, Rambert J, Renouf E, Micouleau M, Mérillon JM. Grape polyphenols and propolis mixture inhibits inflammatory mediator release from human leukocytes and reduces clinical scores in experimental arthritis. Phytomedicine. 2014;21:290-7.

17. Miguel MG, Antunes MD. Is propolis safe as an alternative medicine? J Pharm Bioallied Sci. 2011;3:479_ 95.

18. de Camargo Smolarek P, Esmerino LA, Chibinski AC, Bortoluzzi MC, dos Santos EB, Kozlowski VA. In vitro antimicrobial evaluation of toothpastes with natural compounds. Eur J Dent. 2015;9:580-6.

19. Siqueira AB, Rodriguez L, Santos RK, Marintho RR, Abreu S, Peixoto RF, et al. Antifungal activity of propolis against Candidaspecies isolated from cases of chronic periodontitis. Braz Oral Res. 2015;29:1-6.

20. Pereira E, Silva J, Silva F, Luca M, Ferreira E, Lorenz T, et al. Clinical evidence of the efficacy of a mouthwash containing propolis for the control of plaque and gingivitis: A phase II study. Evidence-based Complement Altern Med. 2011;2011:1-7.

21. Mickenautsch S, Leal SC, Yengopal V, Bezerra AC, Cruvinel V. Sugar-free chewing gum and dental caries: a systematic review. J Appl Oral Sci. 2007;15:83-8.

22. Dodds MWJ. The oral health benefits of chewing gum. J Ir Dent Assoc. 2012;58:253-61.

23. Ercan N, Erdemir EO, Ozkan SY, Hendek MK. The comparative effect of propolis in two different vehicles; mouthwash and chewing-gum on plaque accumulation and gingival inflammation. Eur J Dent. 2015;9:272-6.

24. Rubido S, Fernández-Feijoo J, Limeres J, GarcíaCaballero L, Abeleira MT, Diz P. In vivo antiplaque effect of three edible toothpastes. Med Oral Patol Oral Cir Bucal. 2014;19:88-92.

25. Faul F, Erdfelder E, Lang AG, Buchner A. G*Power 3: A flexible statistical power analysis program for the social, behavioral, and biomedical sciences. Behav Res Methods. 2007;39:175-91.

26. American Academy of Pediatric Dentistry. Guideline on Caries-risk Assessment and Management for Infants, Children, and Adolescents. Clin Guidel Ref Man 20152016. 2015;37:132-9.

27. Frankl SN, Shire FR FH. Should the parent remain with the child in the dental operatory? J Dent Child. 1962;29:150-63.

28. Imfeld T. Chewing gum - Facts and fiction: A review of gum-chewing and oral health. Crit Rev Oral Biol Med. 1999;10:405-19.
29. Al-Hasani M, Hanno A, Dowidar K, Mostafa O, Soliman S. Effectiveness of Egyptian Propolis on Dental Plaque Formation in High Caries. Alexandria Dent J. 2016;41:194-8.

30. Denbesten P, Hee M, Ko S. Fluoride levels in whole saliva of preschool children after brushing with $0.25 \mathrm{~g}$ (pea-sized) as compared $1.0 \mathrm{~g}$ (full-brush) of a fluoriile dentifrice. Pediatr Dent. 1996;182:77-80.

31. Li J, Helmerhorst EJ, Leone CW, Troxler RF, Yaskell T, Haffajee $\mathrm{AD}$, et al. Identification of early microbial colonizers in human dental biofilm. J Appl Microbiol. 2004;97:1311-8.

32. Syed M, Chopra R, Shrivastava V, Sachdev V. Comparative evaluation of $0.2 \%$ Chlorhexidine Mouthwash, Xylitol Chewing Gum, and Combination of 0.2\% Chlorhexidine Mouthwash and Xylitol Chewing Gum on Salivary Streptococcus mutans and Biofilm Levels in 8- to 12-Year-Old Children. Int J Clin Pediatr Dent. 2016;9:313-9.

33. Yang Qiong X, Zhang Q, Lu Ying L, Yang R, Liu Y, Zou J. Genotypic distribution of Candida albicans in dental biofilm of Chinese children associated with severe early childhood caries. Arch Oral Biol. 2012;57:1048-53.

34. Elnakady YA, Rushdi AI, Franke R, Abutaha N, Ebaid H, Baabbad M, et al. Characteristics, chemical compositions and biological activities of propolis from Al-Bahah, Saudi Arabia. Sci Rep. 2017;7:1-13.

35. Sedgwick P. Intention to treat analysis versus per protocol analysis of trial data. BMJ. 2015;350:681.

36. Drago L, De Vecchi E, Nicola L, Gismondo MR. In vitro antimicrobial activity of a novel propolis formulation (Actichelated propolis). J Appl Microbiol. 2007;103:1914-21.

37. Hegde K, Bhat S, Rao A, Sain S. Effect of a propolis extract on Streptococcus mutans counts in vivo. Int J Clin Pediatr Dent. 2013;6:420-3.

38. Ibrahim N, Zakaria AJ, Ismail Z, Mohd KS. Antibacterial and phenolic content of propolis produced by two Malaysian stingless bees, Heterotrigona itama and Geniotrigona thoracica. Int J Pharmacogn Phytochem Res. 2016;8:156-61.

39. Duailibe SA de C, Gonçalves AG, Ahid FJM. Effect of a propolis extract on Streptococcus mutans counts in vivo. J Appl Oral Sci. 2007;15:420-3.

40. Herrera CL, Alvear M, Barrientos L, Montenegro G, Salazar LA. The antifungal effect of six commercial extracts of Chilean propolis on Candida spp. Cienc e Investig Agrar. 2010;37:75-84. 